Original Article

\title{
Effects of single and dual tasks during walking on spatiotemporal gait parameters of community-dwelling older
}

\author{
KyeOngJin LeE, PT, $\mathrm{PhD}^{1)}$ \\ 1) Department of Physical Therapy, Kyungdong University: 815 Gyeonhwon-ro, Huyong-ri, \\ Munmak-eup, Wonju-si, Gangwon-do 26495, Republic of Korea
}

\begin{abstract}
Purpose] This study aimed to investigate the effects of single and dual motor tasks on walking in the elderly. [Subjects and Methods] Data of 308 community-dwelling elderly people were analyzed. Spatiotemporal gait data were obtained using the OPTO Gait system. The gait ability test was conducted under single- and dualtask conditions. [Results] Age and task main effects showed significant difference. Interaction did not show any significant difference. [Conclusion] Our results showed that gait performance decreased during dual task compared to single task. Moreover, we found that the higher the age, the greater the effect on dual tasks. Further research is needed to determine how to improve dual task abilities in older adults.

Key words: Dual task, Gait, Elderly
\end{abstract}

(This article was submitted Jun. 30, 2017, and was accepted Jul. 25, 2017)

\section{INTRODUCTION}

Performing multiple tasks while walking becomes increasingly difficult with age ${ }^{1)}$. Walking in activities of daily living is usually required at the same time as movements of the upper extremities. Performing multiple tasks at the same time results in the loss of performance for individual subtasks ${ }^{2}$. Therefore, performing dual tasks can affect an elderly person's ability to walk ${ }^{1)}$. Changes in cognitive and motor functions due to aging increase balance instability when walking with dual-task ${ }^{3)}$. Unstable equilibrium increases the risk of falls by reducing walking speed and increasing stride velocity variability 2,4$)$.

The effect of walking on dual task performance in the elderly has been studied ${ }^{2,4,5)}$. A dual task is a combination of a single task such as balancing or walking and a cognitive task such as speaking or a motor task such as carrying objects. Most of the research on dual tasks has focused on cognitive tasks ${ }^{2,4,6)}$.

Cognitive dual tasks have a significant impact on gait speed in younger people but less a dramatic effect in elderly people ${ }^{7}$. Elderly individuals reportedly decrease their walking time when performing dual motor tasks such as transporting goods or pressing a button ${ }^{8,9)}$. However, there is little research on dual motor tasks ${ }^{8,10)}$.

Dual motor tasks are frequently required in everyday life. Many routine activities, such as walking with coffee, involve dual motor tasks ${ }^{11)}$. Yang et al. ${ }^{12)}$ reported that dual motor tasks had greater impact on gait reduction than dual cognitive tasks.

A study suggesting that elderly people are affected by performing dual motor tasks while walking did not provide a spatial and temporal gait variable ${ }^{13}$. In addition, since it was a small sample collected from an independent living facility, its findings cannot be generalized to the walking characteristics of all elderly individuals.

Therefore, the purpose of this study is to investigate the effects of single and dual motor tasks on walking in the elderly. We also sought to contribute to the normative database of gait parameters during dual tasks in older able-bodied adults.

Corresponding author. Kyeongjin Lee (E-mail: kjlee@kduniv.ac.kr)

(C2017 The Society of Physical Therapy Science. Published by IPEC Inc.

(c) (1) $\odot$ This is an open-access article distributed under the terms of the Creative Commons Attribution Non-Commercial No Deriva-

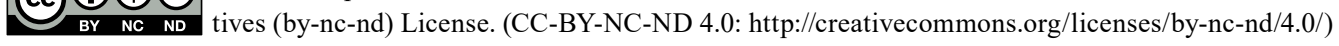




\section{SUBJECTS AND METHODS}

The study included 308 elderly people (mean age, $74.65 \pm 5.32$ years; range, 65-85 years). Subjects were recruited through community organizations and local newspaper advertisements. Older people who met these inclusion criteria were recruited: $\geq 65$ years; and ability to walk $50 \mathrm{~m}$ without an assistive device. Subjects were excluded if they had other neurological, cardiovascular, or musculoskeletal symptoms affecting walking or vision or scored $<24$ on the Mini-Mental State Examination (MMSE). Each study participant provided written informed consent. All procedures were approved by the Institutional Ethics Committee of Sahmyook University.

Power analyses were performed using $\mathrm{G}^{*}$ Power Software version 3.1 with gait speed considered the main variable. We calculated that a minimum of $248(\mathrm{n}=62$ in each group) results would be required to achieve an alpha of 0.05 , effect size of 0.90 (based on a pilot study), and power of 0.95 .

An OPTOGait system (Optogait, Microgate, Italy, 2010) was used to evaluate spatiotemporal gait parameters. The OPTOGait system consists of transmitting and receiving bars, with two bars placed parallel to each other $1 \mathrm{~m}$ apart. The transmitting and receiving bars each have 96 communication light-emitting diodes (LEDs). The LEDs are placed $1 \mathrm{~mm}$ above the floor level of $3 \mathrm{~mm}$. When the subject passes between the transmitting and receiving bars, the system detects the interruption of the optical signal and automatically calculates the spatiotemporal gait parameters because there is a foot in the recording area. The OPTOGait system provides images to users through small synchronized cameras during the detection and testing of all events. The data were extracted at $1,000 \mathrm{~Hz}$ and stored on a PC using OPTOGait version 1.6.4.0 software. The OPTOGait system is widely used in clinical and research environments and features high efficacy and test-retest reliability.

The gait ability test was conducted under single- and dual-task conditions performed in a random order to minimize the effect of training. Three attempts were made for each of the two conditions. Each participant walked through the tray on which the water cup was placed while flexing the elbow at 90 degrees. All tests were performed by a single tester. All participants wore comfortable shoes.

The data analysis was performed using the SPSS 19.0 statistical package. The data distribution of all measured parameters was tested using the Kolmogorov-Smirnov test. The data of all variables were satisfied with the assumption of normality and subjected to the parameter test.

Repeated-measures analysis of variance (four groups, two conditions) and a post-hoc test with Scheffe's test were used to analyze differences in age, gait speed, stride length, and double limb stance duration. Statistical significance was set at values of $\mathrm{p}<0.05$.

\section{RESULTS}

The spatiotemporal parameters of single and dual tasks by age group are shown in Table 1 . The main effects of age and task differed significantly $(\mathrm{p}<0.05)$. Interaction did not differ significantly.

\section{DISCUSSION}

Various tasks must be performed at the same time in everyday life. Humans can generally perform multiple tasks at the same time, but the dual task performance of elderly individuals with reduced cognitive and physical function decreases balance control and mobility ${ }^{12)}$.

This study investigated the effects of single and dual motor tasks on walking in elderly individuals. We also comprehensively analyzed the standard spatiotemporal gait data of the elderly participants by task. Gait quality is dependent on age, health status, and physical function; thus, it is used to assess the risk of cognitive impairment, falls, and premature death ${ }^{14)}$. Verghese et al. ${ }^{15}$ ) explained the walking ability of the elderly in several areas. The gait parameters associated with the execution function include walking speed and stride ${ }^{14,15}$.

Gait speed is an important index of the physical function of the elderly, and when it is reduced by $0.1 \mathrm{~m} / \mathrm{s}$, the risk of falling increases in the elderly ${ }^{15,16)}$.

In this study, gait speed decreased with age. The gait speed difference between single and dual tasks is $0.07 \mathrm{~m} / \mathrm{s}$ for individuals $65-69$ years of age, $0.08 \mathrm{~m} / \mathrm{s}$ for those $70-74$ years old, $0.09 \mathrm{~m} / \mathrm{s}$ for those $75-79$ years old, and $0.13 \mathrm{~m} / \mathrm{s}$ for those 80-84 years old. The difference between the single and dual task was $5.4 \mathrm{~cm}$ for those $65-69$ years old, $5.8 \mathrm{~cm}$ for those $70-74$ years old, $8.8 \mathrm{~cm}$ for those $75-79$ years old, and $11.8 \mathrm{~cm}$ for those $80-84$ years old. The results of this study show that the risk of falls during the dual task condition is increased, while executive function is decreased.

In a study by Silsupadol et al. ${ }^{17}$, elderly individuals $>65$ years of age showed a decreased gait speed of $0.1 \mathrm{~m} / \mathrm{s}$ during the dual- compared to the single-task condition. Freire Júnior, et al. ${ }^{18)}$ reported similar results with a reduction in gait speed of $0.18-0.22 \mathrm{~m} / \mathrm{s}$ and a decrease in stride length of $5.1-5.2 \mathrm{~cm}$ for motor dual tasks in elderly people $>60$ years of age (mean age, 67 years). Himann et al. ${ }^{19)}$ reported that the walking speed decreased by $12-16 \%$ at 10 years after age 70 . Our crosssectional results suggest that gait speed is not significantly different between subjects aged 70-74 years and those aged 75-79 years but significantly reduced in individuals aged $80-84$ years. The gait speed of individuals $80-84$ years of age decreased 
Table 1. Gait parameter by age and task

\begin{tabular}{|c|c|c|c|c|c|c|c|c|}
\hline \multirow{2}{*}{ Parameter } & \multicolumn{2}{|c|}{$65-69(n=85)$} & \multicolumn{2}{|c|}{$70-74(n=80)$} & \multicolumn{2}{|c|}{$75-79(n=71)$} & \multicolumn{2}{|c|}{$80-84(n=72)$} \\
\hline & Single & Dual & Single & Dual & Single & Dual & Single & Dual \\
\hline \multicolumn{9}{|l|}{ Temporal parameter } \\
\hline Velocity (m/s) & $1.3 \pm 1.1$ & $1.2 \pm 0.1$ & $1.2 \pm 0.1$ & $1.1 \pm 0.1$ & $1.2 \pm 0.1$ & $1.1 \pm 0.1$ & $1.0 \pm 0.1$ & $0.9 \pm 0.1^{* \dagger}$ \\
\hline Cadence (steps/min) & $98.0 \pm 6.3$ & $96.5 \pm 6.4$ & $96.2 \pm 6.4$ & $94.1 \pm 5.6$ & $95.4 \pm 5.8$ & $94.7 \pm 6.5$ & $95.0 \pm 7.3$ & $92.3 \pm 8.3^{* \dagger}$ \\
\hline Stride time (sec) & $1.0 \pm 0.0$ & $1.0 \pm 0.0$ & $1.0 \pm 0.0$ & $1.0 \pm 0.0$ & $1.0 \pm 0.0$ & $1.0 \pm 0.0$ & $1.0 \pm 0.0$ & $1.0 \pm 0.0^{* \dagger}$ \\
\hline Step time (sec) & $0.5 \pm 0.0$ & $0.5 \pm 0.0$ & $0.5 \pm 0.0$ & $0.5 \pm 0.0$ & $0.5 \pm 0.0$ & $0.5 \pm 0.0$ & $0.5 \pm 0.0$ & $0.5 \pm 0.0^{* \dagger}$ \\
\hline Double limb stance $(\% \mathrm{GC})$ & $29.4 \pm 3.4$ & $30.5 \pm 3.6$ & $29.9 \pm 2.8$ & $30.7 \pm 3.0$ & $29.9 \pm 4.1$ & $32.0 \pm 3.7$ & $32.9 \pm 3.5$ & $34.9 \pm 4.1^{* \dagger}$ \\
\hline Single limb stance $(\% \mathrm{GC})$ & $70.5 \pm 3.4$ & $69.4 \pm 3.6$ & $70.0 \pm 2.8$ & $69.2 \pm 3.0$ & $70.0 \pm 4.1$ & $67.9 \pm 3.7$ & $67.0 \pm 3.5$ & $65.0 \pm 4.1^{* \dagger}$ \\
\hline \multicolumn{9}{|l|}{ Spatial parameter } \\
\hline Stride length $(\mathrm{cm})$ & $134.0 \pm 12.7$ & $128.6 \pm 12.0$ & $129.6 \pm 14.0$ & $123.8 \pm 12.0$ & $127.1 \pm 15.1$ & $118.3 \pm 12.2$ & $112.2 \pm 15.2$ & $100.4 \pm 11.4^{* \dagger}$ \\
\hline Step length $(\mathrm{cm})$ & $66.8 \pm 6.3$ & $64.2 \pm 6.0$ & $64.6 \pm 6.9$ & $61.7 \pm 5.9$ & $63.4 \pm 7.5$ & $59.0 \pm 6.1$ & $56.0 \pm 7.5$ & $50.1 \pm 5.6^{* \dagger}$ \\
\hline
\end{tabular}

Values are expressed as mean \pm standard deviation.

* Means significant difference between age.

$\dagger$ Means significant difference between task.

by $14.5 \%$ in single tasks and by $19.9 \%$ in dual tasks compared to individuals $70-74$ years of age. This result suggests that even a healthy elderly person can not avoid gait performance deterioration due to aging and that the decrease may cause an executive function deficit. Additionally, there is greater functional loss and a greater risk of falls in the dual task condition than in the single task condition.

According to Verghese et al. ${ }^{15}$ ), cadence and temporal parameters are associated with memory impairment and dementia. Therefore, it is important to understand the normative value of these variables. Cadence in the present study was 0.02 steps/ min for those 65-69 years of age, $0.02 \mathrm{steps} / \mathrm{min}$ for those 70-74 years old, $0.01 \mathrm{steps} / \mathrm{min}$ for those $75-79$ years old, and $0.03 \mathrm{steps} / \mathrm{min}$ for those $80-84$ years old. In this study, cadence did not differ significantly between age groups or tasks. The subjects of this study were healthy elderly people with normal cognition (MMSE score $\geq 24$ points), and it was difficult to confirm the relationship between cadence, memory, and dementia.

Double limb stance is a variable that reflects balance disturbance during walking ${ }^{20)}$. The increase in double limb stance affects the decrease in gait speed and stride length and is associated with an increase in age and double limb stance ${ }^{21,22)}$. When people simultaneously perform dual tasks, attention should be distributed between them ${ }^{13)}$. At this time, if the available resource capacity is exceeded, the performance of one or both of the tasks becomes hindered ${ }^{23)}$. In this study, the difference in dual limb stance between single and double tasks was 3.8\% in individuals $65-69$ years of age, $2.6 \%$ in those $70-74$ years old, $7.2 \%$ in those $75-79$ years old, and $6.0 \%$ in those $80-84$ years old. These findings suggest that attention to balance and the dual task was reduced during walking.

Since double limb stance is a variable that reflects disturbances during walking, the increase in double limb stance also affects the decrease in gait speed and stride length ${ }^{21,24)}$. The results of this study show that double limb stance was increased in the dual task condition, while gait speed and stride length were decreased compared to those of the single task condition. Double limb stance increased with age, while gait speed and stride length decreased. Our results showed that gait performance decreased during the dual task condition compared to the single task condition. We also found that the more advanced the age, the greater the effect on the dual tasks.

The limitation of this study was that the subjects walked at their own selected speed rather than at maximum speed. Thus, the results of this study should not be interpreted as those of the subjects' maximum walking ability.

This study has several strengths. First, the study sample was large and the participants were all healthy communitydwelling elderly adults. Thus, our results are expected to be generalizable to the larger elderly population. Second, the data in this study were collected from an average of $18 \pm 4$ steps (nine strides) per person. We believe that our data are reliable because they were collected from more strides than those of previous studies. Third, test variability was minimized by the use of a single evaluator.

Despite our findings, further studies are needed to determine how to improve dual task abilities in older adults.

\section{REFERENCES}

1) Hollman JH, Kovash FM, Kubik JJ, et al.: Age-related differences in spatiotemporal markers of gait stability during dual task walking. Gait Posture, 2007, 26: 113-119. [Medline] [CrossRef]

2) Yogev-Seligmann G, Hausdorff JM, Giladi N: The role of executive function and attention in gait. Mov Disord, 2008, 23: 329-342, quiz 472. [Medline] [CrossRef] 
3) Tseng BY, Cullum CM, Zhang R: Older adults with amnestic mild cognitive impairment exhibit exacerbated gait slowing under dual-task challenges. Curr Alzheimer Res, 2014, 11: 494-500. [Medline] [CrossRef]

4) Lacour M, Bernard-Demanze L, Dumitrescu M: Posture control, aging, and attention resources: models and posture-analysis methods. Neurophysiol Clin, 2008, 38: 411-421. [Medline] [CrossRef]

5) Guedes RC, Dias RC, Pereira LS, et al.: Influence of dual task and frailty on gait parameters of older community-dwelling individuals. Braz J Phys Ther, 2014, 18: 445-452. [Medline] [CrossRef]

6) Beauchet O, Dubost V, Gonthier R, et al.: Dual-task-related gait changes in transitionally frail older adults: the type of the walking-associated cognitive task matters. Gerontology, 2005, 51: 48-52. [Medline] [CrossRef]

7) Yogev-Seligmann G, Rotem-Galili Y, Mirelman A, et al.: How does explicit prioritization alter walking during dual-task performance? Effects of age and sex on gait speed and variability. Phys Ther, 2010, 90: 177-186. [Medline] [CrossRef]

8) Ebersbach G, Dimitrijevic MR, Poewe W: Influence of concurrent tasks on gait: a dual-task approach. Percept Mot Skills, 1995, 81: 107-113. [Medline] [CrossRef]

9) Laessoe U, Hoeck HC, Simonsen O, et al.: Residual attentional capacity amongst young and elderly during dual and triple task walking. Hum Mov Sci, 2008, 27: 496-512. [Medline] [CrossRef]

10) Lundin-Olsson L, Nyberg L, Gustafson Y: Attention, frailty, and falls: the effect of a manual task on basic mobility. J Am Geriatr Soc, 1998, 46: 758-761. [Medline] [CrossRef]

11) Canning CG: The effect of directing attention during walking under dual-task conditions in Parkinson's disease. Parkinsonism Relat Disord, 2005, 11: 95-99. [Medline] [CrossRef]

12) Yang YR, Chen YC, Lee CS, et al.: Dual-task-related gait changes in individuals with stroke. Gait Posture, 2007, 25: 185-190. [Medline] [CrossRef]

13) Oh-Park M, Holtzer R, Mahoney J, et al.: Motor dual-task effect on gait and task of upper limbs in older adults under specific task prioritization: pilot study. Aging Clin Exp Res, 2013, 25: 99-106. [Medline] [CrossRef]

14) Hollman JH, McDade EM, Petersen RC: Normative spatiotemporal gait parameters in older adults. Gait Posture, 2011, 34: 111-118. [Medline] [CrossRef]

15) Verghese J, Holtzer R, Lipton RB, et al.: Quantitative gait markers and incident fall risk in older adults. J Gerontol A Biol Sci Med Sci, 2009 , 64: 896-901. [Medline] [CrossRef]

16) Cesari M, Kritchevsky SB, Penninx BW, et al.: Prognostic value of usual gait speed in well-functioning older people-results from the health, aging and body composition study. J Am Geriatr Soc, 2005, 53: 1675-1680. [Medline] [CrossRef]

17) Silsupadol P, Shumway-Cook A, Lugade V, et al.: Effects of single-task versus dual-task training on balance performance in older adults: a double-blind, randomized controlled trial. Arch Phys Med Rehabil, 2009, 90: 381-387. [Medline] [CrossRef]

18) Freire Júnior RC, Porto JM, Marques NR, et al.: The effects of a simultaneous cognitive or motor task on the kinematics of walking in older fallers and nonfallers. Hum Mov Sci, 2017, 51: 146-152. [Medline] [CrossRef]

19) Himann JE, Cunningham DA, Rechnitzer PA, et al.: Age-related changes in speed of walking. Med Sci Sports Exerc, 1988, 20: 161-166. [Medline] [CrossRef]

20) Maki BE: Gait changes in older adults: predictors of falls or indicators of fear. J Am Geriatr Soc, 1997, 45: 313-320. [Medline] [CrossRef]

21) Elble RJ, Thomas SS, Higgins C, et al.: Stride-dependent changes in gait of older people. J Neurol, 1991, 238: 1-5. [Medline] [CrossRef]

22) Woo J, Ho SC, Lau J, et al.: Age-associated gait changes in the elderly: pathological or physiological? Neuroepidemiology, 1995, 14: 65-71. [Medline] [CrossRef]

23) Palluel E, Nougier V, Olivier I: Postural control and attentional demand during adolescence. Brain Res, 2010, 1358: 151-159. [Medline] [CrossRef]

24) Gabell A, Nayak US: The effect of age on variability in gait. J Gerontol, 1984, 39: 662-666. [Medline] [CrossRef] 